\title{
Increasing Value of Architecture in the Platform Society
}

\author{
M. N. Pool \\ Director Space \& Matter \\ pool@spaceandmatter.nl
}

\begin{abstract}
The author has developed several methods for democratizing the architectural design process resulting in a more user specific and open architecture. Our cities need Open Systems in order to grow and become resilient and not rigid ones. People should be able to change the environment they live in, the longer they live in them. The city's Eco-System is about equilibrium and balance, for a city to evolve, this balance is important. The city needs to remain open and unpredictable in order to be resilient. This paper describes which Open Process and tools result in creating Open Buildings. The authors mission to aim for an Open City is being described by implemented case studies. The author's experience and theoretical framework is being developed synchronously. Since architecture and urban design touches on all levels of society, space\&matter involves a wide spectrum of disciplines in their design and development process. Before configuring space, understanding socio-cultural processes adds relevance to our designs; our objective is connecting people and their environments. In order to reach a high level of connectivity in the built environment it's relevant to Open up the Design Process. Experts, stakeholders and also end-users can collaborate in the process of creation from an early stage. This makes our architecture more specific and more sustainable.
\end{abstract}

Keywords: Democratization; Self-organization; Community building; Open system; Inclusivity

\section{The Value of Architecture; Capital no Capital}

Seeing the influence of Capital on architecture. To what extent does the availability of capital result in good architecture? As architects are complaining about the lack of budget, how can one make good architecture if there is no availability of an adequate budget? But if there is an unconstrained amount of capital, is does not stimulate nor generate good architecture. What is the good condition for architecture to emerge? And what is the influence of Capital? For example in London - empty urban districts, which actually represent the mere storage of Russian Rubles or Chinese RMB's, the real estate stock as a safe haven for foreign capital to be stored. The actual value of the residence, the place it is built in, the atmosphere it breathes is not gained. The static and latent stock of monetary value is sucking out the societal value out of the neighborhoods... leaving an alienated neighborhood.

Das Kapital is a Book by Pikkety explaining the influence of capital on the distribution of wealth. The basic message is that the inequality between 'haves and not haves' will increase. The ones that have or have access to Kapital are able to gain from the growth of capital. The ones that don't have capital will have to be employed. But being employed means paying rent for a residence and services. While prices increase; the current generation will not be able to build up capital. How can we make the city, the buildings, and thus the architecture less dependent on capital? There is a lot more value out there than monetary value. So let's start talking about value and not money.

Design and Development tenders aiming at the submission of the highest bid, cannot result in the highest quality of architecture. What is the aim of opening up calls for the highest bid? What if the highest bid needs to be translated as the bid proposing the highest value? The highest value should be seen as the highest total value. Value is more than the monetary explanation. Value is not singular nor one-dimensional. Value is a complex matter composed of interpretations and acceptations. The 
cultural value or historical value are strong parameters to be judged. But also social value; the societal value in terms of amount of jobs created. Or the educational value; every project is an important learning potential. Taking an inclusive approach to value, will also require a more inclusive approach to proposing a call. We believe in the value of communities, the value that every individual represents. A collection of individuals is a rich pool of talents and skills. We see an architecture that can emerge from the social capital of the residents that inhabit it. Like a co-housing project that is co-funded by it's future owners. No developers and no investors are necessary in the process...

\section{Hope and Perspective}

Building cities on the foundations of social capital makes them the breeding ground for long lasting strong networks of connected individuals. Groups and collectives respect each other and are generous. Stimulating environments in which an individual's talent is seen as the maximum potential to be exposed and creating urban conditions in which this is optimally orchestrated should be seen as Practical Utopias. Making ideological vision into hyper real and tangible proposals. Making concepts, drafting strategies and thinking about activist interventions all have the strong focus and goal to establish the condition for happier communities. A high sense of belonging is an important ingredient, the degree of participation in the process, the level of trust and reciprocity. The social capital is our largest asset and can be multiplied if we are capable of envisioning and concretizing the HappyCity.

Building cities on the foundations of trust will foster communities with thriving happy people. Happiness emerges when people feel connected to each other and to their physical environment. There is no more crucial ingredient for human happiness than strong, positive social connections. Connected communities are happier, more resilient in hard times and better equipped to handle economic challenges.

\section{Problem Statement}

Entering the $21^{\text {st }}$ century has brought us a lot more wealth, more independence, more devices to assist us in our well-being. But at the same time it has made us more independent and actually more disconnected. The automobile is an individual cocoon extracting a person from the public life in the street. The mobile phone is creating a digital bubble the individual can escape in. The devices, the autonomous behavior, has increased our independence, yet has made us more isolated... We see an enormous increase in the disease of loneliness in cities. We feel we are part of a crowd, but feel lonely and impersonal. We live very closely together, but are segregated at the same time. We live in parallel realities. How can we embrace all the benefits of $21^{\text {st }}$ century inventions and technologies to make our urban environments more Inclusive? Not a high level of wealth, but feeling rich with the amounts of friends we have... Feeling rich because our talents can be deployed. Feeling rich, because we are free. The freedom of not living with the burden of a mortgage and the ownership of too many goods. Footloose living...? Do we have to go back in time and look at nomads? Living within the direct context and co-existing with the resources the context and the season provides.

\section{Making Inclusive Cities}

A City's evolution was based on clusters of people that functioned well in balance with their direct natural resources, which was also a limitation for its growth. The industrial revolution and especially the start of the coal era made the city free to expand. Railways, roads and bridges made sure the city's reach goes far beyond its hinterland. This is where the city as an organic self-organized ecosystem got out of balance. Nowadays we see the city function as nodes in a very well connected network of cities. These networks develop fast and their scale and complexity rapidly increase, while there are acknowledgements for negative environmental effects. The Connected City sees opportunities for an Imploding City rather than an Expansive City. While cities continue to grow we don't need its physical 
substance to increase. As designers we aim at contributing to the built environment by providing holistically designed structures that incorporate flexibility and adaptability from an early stage in the design process as well as throughout the life-cycle of a building. We rather see buildings as collective resources, which can be used more effectively in order to cater for societies' expanding needs. Seeing the City as an Open System makes us think about the buildings as Open Buildings functioning in this Open System. Design and planning incorporates thinking about organization; through networks, a high level of self-organization can be reached.

Cities accelerate economic transformation because of their intense population densities, which encourages social and economic interactions with greater social friction than non-urban settings. An estimate says that $54 \%$ of world population lives in cities; by 2050 , the percentage is expected to reach $66 \%$. City dwellers have $30-50 \%$ smaller $\mathrm{CO} 2$ footprints than rural and suburban residents. If so many people live in cities, then it's important that city making is done in close collaboration with all actors, especially urban dwellers. If city planning is not inclusive, people might start to feel that its useless to take action. The planning process and outcome must be socially inclusive; marginalization of groups of urban actors must be prevented (Timmeren, 2015). In our research we aim for the Inclusive City, in which a direct interaction in the creation of the built environment is crucial. Facilitated through an Open Process, the realization of Open Buildings is effectively and innovatively taking shape. On the basis of the research of multiple case studies the author provides knowledge and understanding of methodologies and tools contributing to empowering citizens in shaping their city. The Open City vision underlying these methodologies revolves around self-organization, Open-Systems, platforms and collectivity in the understanding of the Commons. On the basis of the Networked Society, the Networked City will become the Inclusive city.

\subsection{How Intelligent are Smart Cities}

Smart Urban development opens up new opportunities at the crossroads of the physical and the digital aspects of the urban domain, resulting in solutions that could fundamentally transform and accelerate the development of cities as well as their ability to change. In order to function well as smaller networked environments it is necessary to increase the level of diversity and connectedness. Heterogeneous programs and close-knit networked environments are more capable to reinvent themselves and to be resilient for change. The concept of resilience is seen as a useful way of understanding, and explaining, how social-ecological systems respond to change and disturbance. It is also seen as a desired attribute of cities in modern urban planning and management strategies. A focus on resilience and the resulting strengthening of the self-organization capacity of urban systems is also regarded as a means of improving the sustainability of cities (Gibberd, 2013). Diversity and adaptability are strong contributors to a city's well-balanced Ecosystem. The level and scale of diversity is furthermore discussed in relation to Openness. This paper aims at creating an understanding of how the Open City and Open Buildings can be more resilient, and perform better in the continuous process of transformation in an evolving and changing society.

\subsection{Use of Open Systems to Create Connected Cities}

The Open City as an Open System however is evolving as a system of constant change and providing a test-bed for experiment and innovation. ICT and the internet have allowed people to communicate with each other more than ever before, yet leaving many people with an increased sense of uncertainty, anxiety, isolation and alienation (Timmeren, 2015). The more we rely on impersonal modes of digital communication the more we may be loosing the intimacy and depth of social and physical correspondence. In order to rebuild this relation, people need to connect to their physical environments and to their social structures and networks within their environments from which we have grown 
detached. The increase in independency because of communication and mobility has diminished the physical connectivity and replaced it with a high level of virtual connectivity. (Grillo, 2005).

The question of what we want our future urban spaces to look like cannot be separated from what kind of people we aspire to be. We must go beyond the individuals' right to have access to the resources the city provides, towards the right to change and re-invent the cities (Harvey, 2014). The freedom to make and remake ourselves and our cities is the most precious yet the most neglected of our human rights. (Robinson, 2013). The illuminated City as Arjan van Timmeren refers to is citizen-focused, community defined, open-source cities that harness technology to enhance democracy and distribute governance, support individual and collective autonomy, community participation in urban planning and enshrines the citizens right to privacy.

Democracy in the Open City is a situation where the facts, beliefs and practices of society are forever examined and confronted. For it to flourish; spaces of confrontation must exist and contestation must occur. Study of networks is complexity theory, in which one very essential concept is the Complex Adaptive System (CAS) and its characteristics of emergence and self-organization are described. Taking action will also result in Reaction, on micro and macro level that is what makes the city work. As long as there is a sense of ownership and the ability to participate and take action; one possesses the feeling of belonging and being part of the city. This also attaches an individual to the collective identity of a city. If all relevant stakeholders are included and heard than the social capital which is drawn upon is largest. The higher the level of diversity of the social and cultural capital, the higher the increase in adaptive capacity, which enhances resilience in the face of external shocks and rapid change.

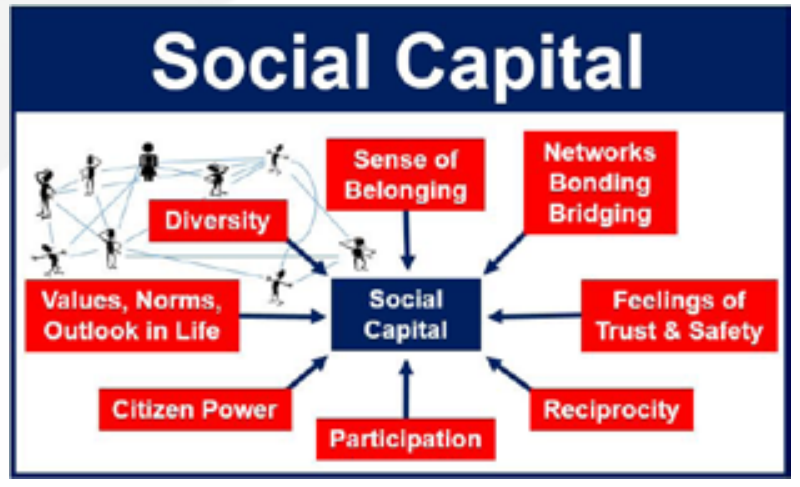

Figure 01: Values of connections and social capital.

\section{Case Study: Open City Planning Model}

Towards urban planning the conventional masterplan is dismantled and replaced by a more organic model of interactive city making. In the Open Kaart proposal, Space\&matter has moved from a tactical urbanism to a strategic urbanism by facilitating an emergent model to express the city's latent desires. This means that we as designers are not 'master planning' an urban district, but rather provide a stimulative framework within which substantial degrees of freedom are generated. Stepping down from a top-down master's perspective we facilitate the users perspective and lower the threshold for individuals to be part of city making, as well as collectives and not to forget the professional and institutional parties. Doing so we provide a level-playing field for multiple actors to give expression to their desires. The Open Kaart model consists of a simple set of rules and guidelines. On a macro level infrastructure, green axis and routing has been determined. The 'infill' of this so-call urban 'structure' is provided by tangible building envelopes and subdivision of plot sizes. The scale and proportion of one's 
interest is fostered by the plot size and the prescribed capacity of the potential development. As such the city planning process has become a collective act. Especially for the individual the large degree of freedom is combined with affordability since it's open for real people, with real houses, funded by real money. By providing a greater diversity of engaged citizens a stronger social fabric is established.

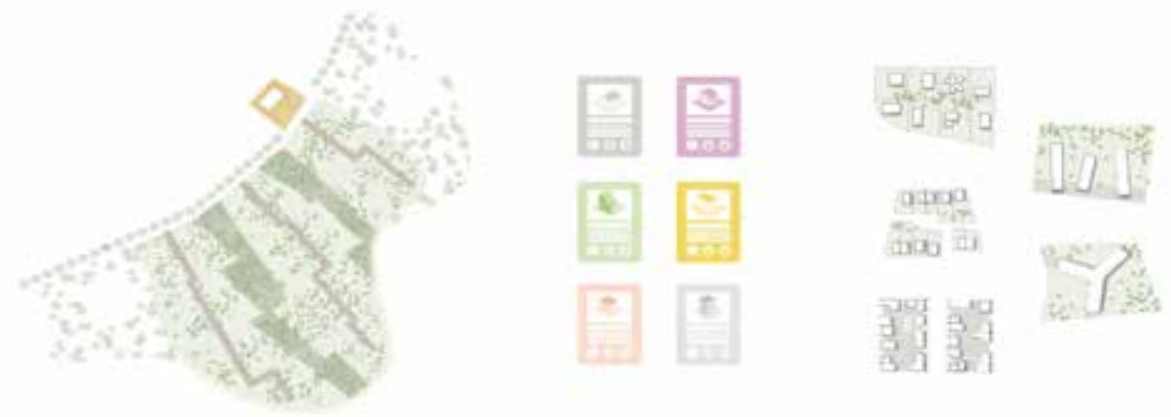

Figure 02: Open Kaart Attributes; site, building envelopes, configuration.

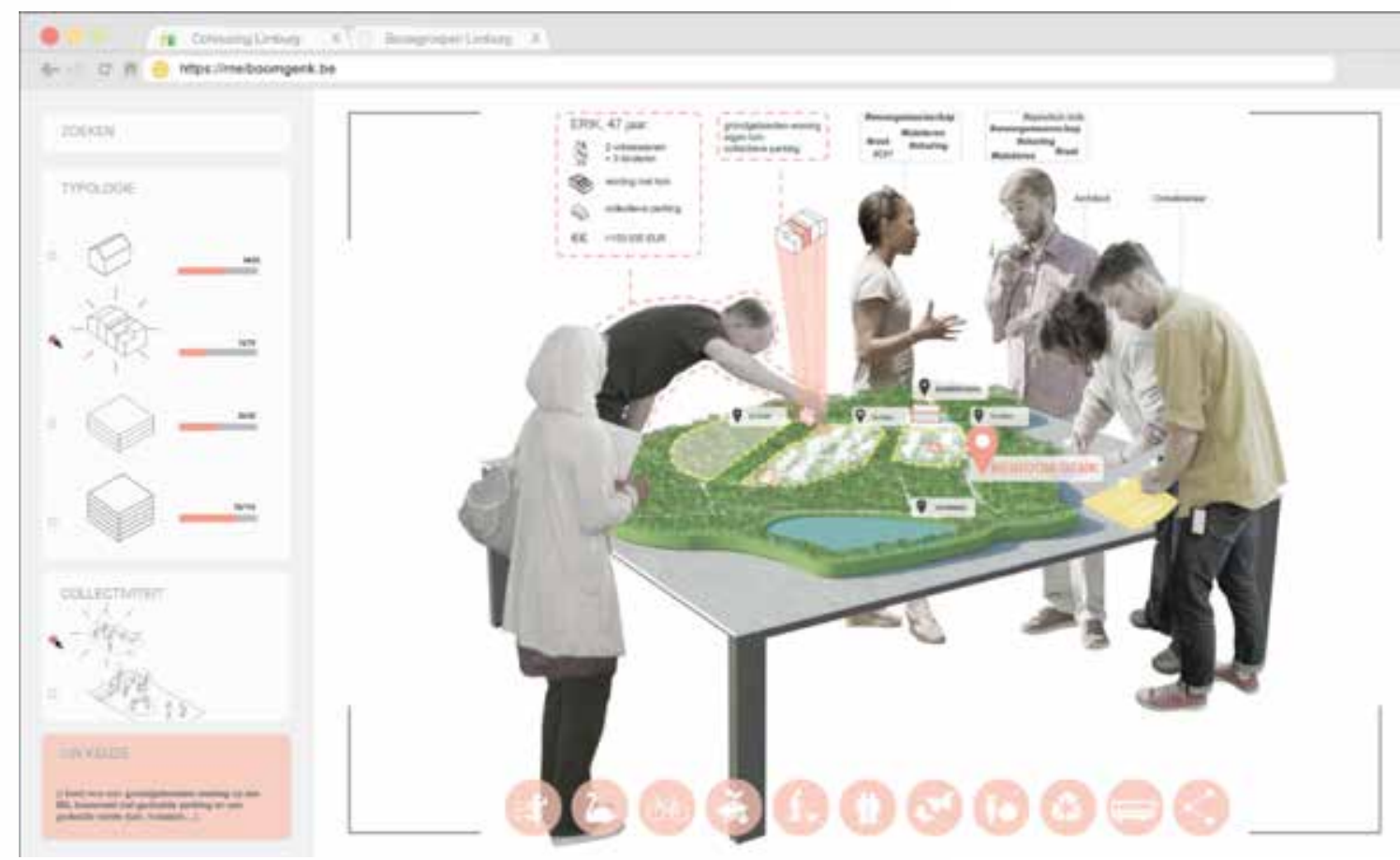

Figure 03: Open Kaart: open planning toolkit.

Case study: SchoonSchip Amsterdam

Schoonschip envisions the design \& development of a Resilient and Circular Floating Community. Space\&matter has catalyzed the group clustering process by providing feasibility studies and visualizations. In close collaboration with the group, we developed the urban plan consisting of 30 houseboats, housing 46 families along a 900 -sqm jetty. The floating neighborhood is divided into 5 interconnected clusters. The jetty forms the backbone for the floating community. It serves as public space and creates unity in the urban design. Its specific form allows rotated positioning of the houseboats and therefore better views and visual connections. To meet the diversity of the group and to promote variety in architecture, we developed 5 houseboat typologies of various size and shape. For each typology we created a set of rules and defined the maximum building size so that each household could easily instruct 
their own architect. The Open City approach in this project has been very successful, since it allows high degrees of freedom for the individual while realizing a strong collective identity.
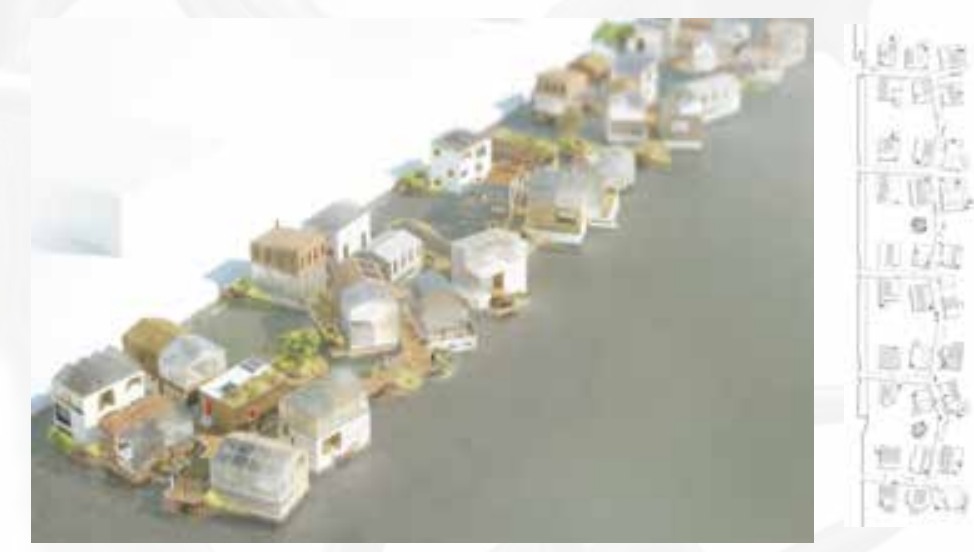

Figure 04: Schoonschip: floating, self-supportive neighborhood based on autonomous city making.

\section{Connecting Citizens to Cities}

The social behavior expressed by users of the internet is a valuable resource to determine the Collective. This entity, which we refer to as the Collective, is a group of individuals organized around a set of common values that bonds them together. On the basis of a developed model called Interestbased-urbanism, Space\&matter defines the positive and negative aspects of developing Architectural models in the age of the Platform Society. Tools to reach out to individuals and collectives enables Space\&Matter to interact and closely involve end-users in the early stages of the design process. This Open-Design-Process is developed in a layered set of Degrees of Freedom. Based on SocioEconomic or Socio-Cultural specificities, different approaches can be applied to provide the necessary level of end-user satisfaction. The constant aim is to provide a maximum level of customization while maintaining its affordability. Doing so Space\&matter has proven to be capable of designing Residential Open Buildings that contribute to our mission of establishing a more Open City. The strong focus on social inclusion and sustainability has resulted in a diverse cluster of end-users in the collective buildings, which we refer to as Community Buildings. This diversity contributes to a building's Socio-Cultural and Economic Robustness. The diversity and 'Pluralicity' in the buildings program maximizes the building's potential. By increasing, the chance for encounters and the sharing of ideas a Collective housing scheme needs to maintain its Openness. This Openness is crucial for its future existence to prevent the building from isolating itself.

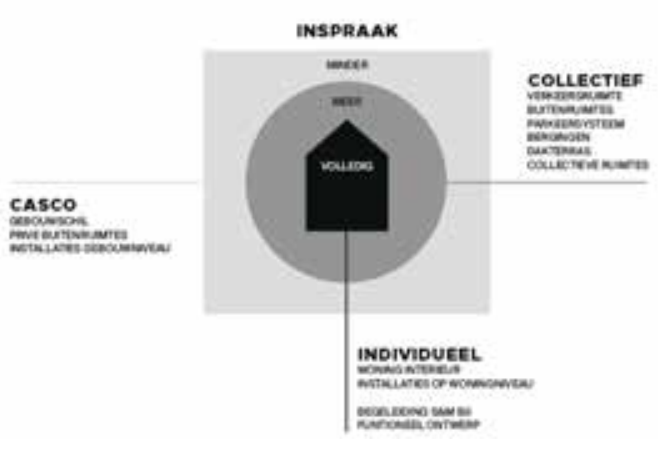

Figure 05: Spheres of influence.

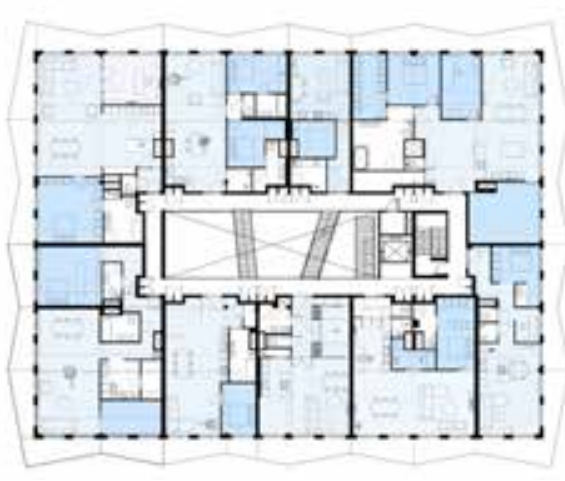

Figure 06: Individual houses around collective court. 


\subsection{Specificity and Affordability}

For long, architects are dealing with the balance to make architecture affordable as well as local and explicit, to its end users' demands. It was in the beginning of the $20^{\text {th }}$ century that Le Corbusier invented the Dom-Ino house, which was a blue print model to effectively provide an affordable solution for the high demand of affordable housing. The combination of Domus and Innovation provide an Open and standardized module without walls and partitions. These basic modules could easily be combined and clustered. Perhaps this was the first architectural house designed as an open-system, for residents to complete as they see fit. The Dom-Ino functions as a platform, just as well as the Henry Ford Assembly line was an affordable alternative by mass-producing cars. Today most homes on the planet are still built without architects. The radical part of the Dom-Ino house is that it is merely the beginning of a process since it needs completion by the residents themselves. It is the abandonment of Total Design (McGuirck, 2014). Stewart Brand has also described this ideal in his book 'How Buildings Learn'. Brand argues that buildings work best when they evolve gradually and incrementally. In todays architecture we see a strong movement that advocates the need for self-empowering systems and not finished houses. Personalization and customization are integral parts of todays society, however customizing the built environment is still lacking behind in this development curve. The different degrees of freedom allow for different levels of interaction with the end-user thus allowing them to customize their built environment and to empower them in a very direct way.

\section{Case study: ObjectONE:}

ObjectONE can be best described as the stacking of self-built houses. Future owners choose from three plot sizes; single story with a 2.80 free height, double height plot for houses with a 5.80 height en roof-plots with diagonal roofs for solar panels. The design and infill provide the largest degrees of freedom. Owners can design their own homes by assigning their own architect and eventually the contractor for execution. Besides they have the option to choose from a selection of 'ready-made' designs. Doing so the design is explicit in type, style and budget, but provides certainty from the start. The interiors of these ready-made designs can still be customized in their interior fit-outs.
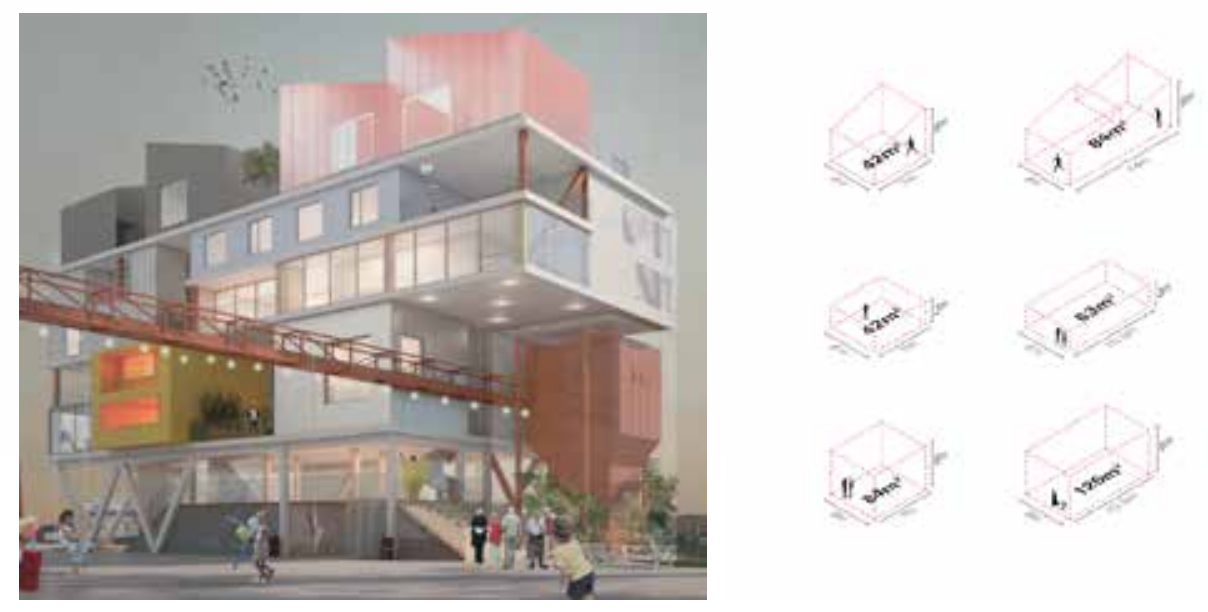

Figure 07: ObjectONE Collective assembly of individual units.

\subsection{Interest Based Urbanism}

The concept of 'interest-based-urbanism' derives from the notion of the behavior we detect within society. We see a schism between people in their offline living environment, in which they don't know their direct neighbors, with whom they share a corridor and entrance. While at the same time we see a 
very strong online social behavior where we're intensely connected to our interest groups, hobby forums or whichever reason to self-organize a smaller group of the like-minded. We develop (online) tools that assist us in making more inclusive and connected environments by proposing a translation of the online behavior into its offline behavior and physical manifestation. In other words; wouldn't it be possible to start living together with the people with whom you share most interests? This would allow a residential building to also cater for shared spaces, like sharing a music studio, or a children day-care space.
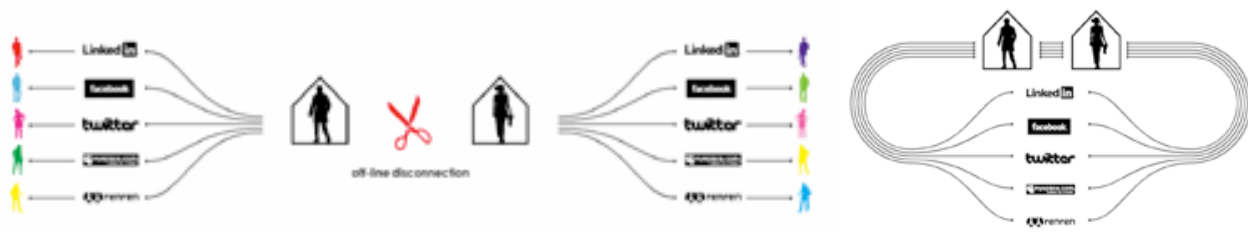

Figure 08: Offline disconnected while online connected

Case Study: CrowdBuilding:

Detecting the fact that individuals are social beings and like to live together; we envisioned CrowdBuilding, where we see that in society people easily flock together on social media and the internet. We see the opposite in the off-line environment. We asked ourselves 'is there a way to make the high level of online connectivity reflect a high level of connectivity in real space?'. CrowdBuilding is an online platform, which facilitates individuals to express their individual and collective needs. Doing so we see the common denominators between individuals. The functionality of the online platform stimulates to join crowds and to initiate crowds. A crowd defines a collective interest, such as 'gardening, children playground, music studio, etc.' By clustering multiple individuals around a common interest we detect a certain kind of demand. On the basis of this demand a specific supply will be proposed. So we start to make a custom made design, custom towards the collective entity. Doing so, CrowdBuilding kick starts new developments based on prove demand. This method for development initiation is radically changing the process of development \& design. Similar to ObjectONE, the cluster of individuals become the crowd-funders for their own living environment. This high level of enduser participation and collaboration results in interesting building typologies and social arrangements. With CrowdBuilding we are adding quality to the program of the building. Where the building itself becomes the facilitator for this inherent program of demands. (www.crowdbuilding.nl)
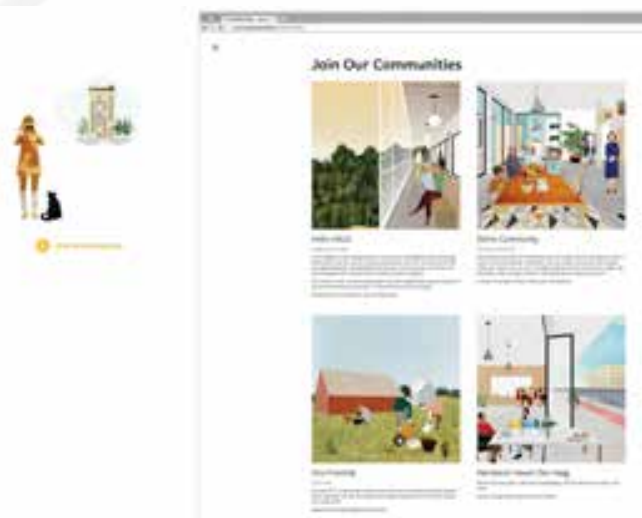

Figure 09: Online platform to facilitate communities.

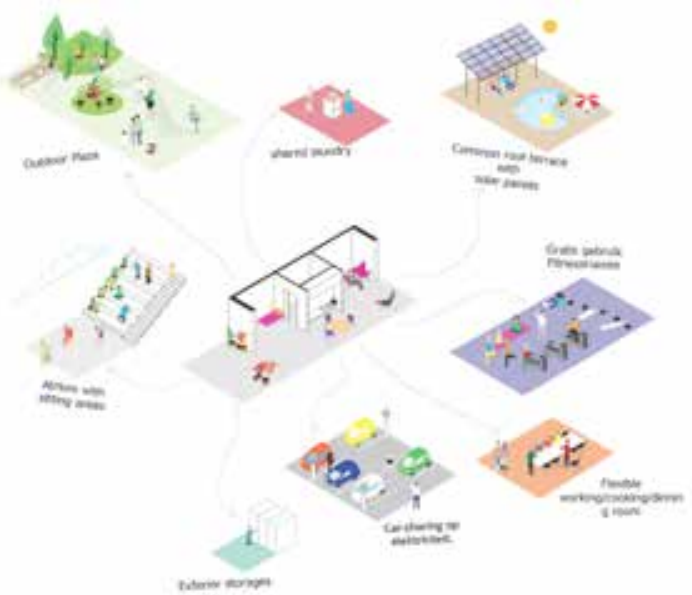

Figure 10: Sharing facilities with direct neighbors. 


\section{Conclusion}

Providing high quality living environments for affordable budgets is necessary in our urban contexts. By using the power of the Commons and tapping into the self-organizing potential of residents, Space\&Matter has proven to be capable of realizing highly customizable architectures. Specificity is about expressing the character of its inhabitants, not as a direct translation but rather as an expression of values and standards. Architecture has the capability to act as a medium for the desired selfrealization. Reaching this high level of satisfaction is being enabled by an Open-Process approach in Architectural design. The Empowerment of the end-users is crucial. The level of interaction is instrumental for the outcome. Architectural success is a collective achievement. Architecture is not framed by the definition of Design, which the end state is a product of, but rather a continuous process of negotiation and accumulation, of a collective effort and building upon collective intelligence. Added value is created by establishing a well-functioning software (neighborhood structure) inside the hardware (architecture). Building up social capital and providing strong identities makes unique architectural projects more sustainable and resilient. Creating a city by incorporating $21^{\text {st }}$ century tools and platforms enables space\&matter to effectively work closely together with end-users by eliminating unnecessary actors in the development and design process. The outcome gets more valuable while proven to be more affordable.

\section{Bibliography}

Gibberd, Assessing and Intervening: Urban Resilience Indicators.

Harvey D. 2014 seventeen contradictions of capitalism.

https://www.academia.edu/4400216/Assessing_and_Intervening_Urban_Resilience_Indicators

https://www.dezeen.com/2014/03/20/opinon-justin-mcguirk-le-corbusier-symbol-for-era-obsessed-withcustomisation/

Justin McGuirk 2014, Le Corbusier symbol for an Era Obsessed with Customization.

Robinson R. 2013, the sharing economy

Timmeren, A. (2015)., Ubikquity

Cite this article as: Pool M.N., "Increasing Value of Architecture in the Platform Society", International Conference on the $4^{\text {th }}$ Game Set and Match (GSM4Q-2019), Doha, Qatar, 6-7 February 2019, https://doi.org/10.29117/ gsm4q.2019.0010 